\title{
Mathcad in the Civil Engineering Curriculum
}

\author{
Brian L. Houston \\ University of Pittsburgh at Johnstown
}

\section{Introduction}

The core curriculum for civil engineering and civil engineering technology programs has not changed significantly over time. Courses in statics, dynamics and strengths of materials attempt to teach the same concepts as were taught decades ago. The difference lies in how these concepts are visualized, the teaching methods employed by the instructor and the development of computer-aided design.

Many institutions have added entry-level courses specifically aimed at providing students with basic skills in various software packages reflecting the technology used in the practice of engineering. Without reinforcing these basic skills in upper-level courses by demonstrating applications that use the software, the student may perceive the introductory course as having been a waste of time and money.

In civil engineering, the development of Mathcad by the software firm Mathsoft has provided the civil design engineer a valuable tool capable of producing calculation packages that are both readily modified and easily reviewed. The need for "reviewability" is more acutely felt in the civil engineering discipline because the practice of civil engineering often includes reviewing and sealing calculations. When accepting the liability that accompanies the sealing of documents, the civil engineer gains comfort from calculations that are clear, concise and well annotated. While the licensure issue and its inherent risk are not unique to civil engineering, they are not as prevalent in other engineering disciplines.

Students can realize the advantage of using Mathcad when the instructor emphasizes the risk control and revenue generating aspects of the software. To highlight these benefits, specific assignments can be made in a variety of courses to show the versatility of the software and to demonstrate how specific application development can reduce the design cycle for future projects. The reduction of the design cycle can have a dramatic effect on profitability in lump sum contracts. Additionally, the uniformity provided by development of standardized documents, particularly in Mathcad due to its ease of review, aides in reducing risk by minimizing errors in computations. 


\section{Software and Civil Engineering}

Civil engineering and engineering technology curricula have gradually changed to accommodate the needs of specialized areas of design and the ever changing world of computer-aided design, while still giving adequate treatment to the basics of the discipline. In many instances this has forced students to either increase their credit-hours per term or reorganize their education into an extended program of five or six years. Facing these challenges, students need to understand how the design aids they are shown can benefit them. Without this understanding they become frustrated and eventually do not have confidence in the software applications presented.

The software world of the civil engineer has historically included spreadsheets. The dominant spreadsheet used today is Microsoft Excel. While this format is generally useful in processing large amounts of data or for performing simple calculations, it is cumbersome for complex formulae. For example, keeping track of parentheses is difficult for long equations used in spreadsheets. Also, unit conversions must be accounted for in the equations since the software does not have a unit conversion "engine”. Spreadsheet calculations are difficult to modify, particularly when the document was not originated by the reviser. The printed report for spreadsheet calculations is often difficult to follow and seldom includes all of the formulae for review.

The process of structural analysis has its own unique software market. The analysis program Staad has been a market leader in structural design software for many years. Newer programs such as GD STRUDL, RISA and a multitude of similar programs have slowly gained market share and now offer the design engineer many options for complex structural analysis problems. While this software is ideal for large, complex structures, the initial set-up for small structures may not be cost beneficial.

A large portion of the civil engineering design world involves calculations that are somewhat complex for designing in a spreadsheet but not complex enough to warrant the expense of a highend structural analysis packages. One example would be crude oil tanks. This design work involves standards that are outside the scope of typical building codes (BOCA, NBC, IBC) due to the hydrodynamic effects of sloshing liquids. Since most off-the-shelf analysis products do not include specialized design code criteria, they are not useful for niche-markets. Specialty design may also require plate stress analysis, pressure venting, custom appurtenances among many other possible requirements. No one software application does all of this.

A general format calculation package that is user-customizable is much more advantageous in specialty design applications. Mathcad offers such a platform. The user starts with a blank sheet and can develop calculations for many disciplines. The final calculations can be formatted to produce a clean, concise, report-style document that is easily reviewed. In addition the software has features which allow the developer to conceal proprietary information and deter other firms from acquiring sufficient information to reverse engineer their design process.

"Proceedings of the 2005 American Society for Engineering Education Annual Conference \& Exposition Copyright (C) 2005, American Society for Engineering Education” 


\section{Software in the Curriculum}

How does the instructor convince the student of the value in a specific product, in this case Mathcad? Many students evaluate worth in terms of monetary value. Upper class students who have discussed liability issues can see value in risk management tools. Profit potential and liability reduction can be readily demonstrated by highlighting the speed of performing repetitive work tasks and the mitigation of liability by developing standardized documents which are both powerful features of the Mathcad product.

Like any software tool, the user must first gain a rudimentary knowledge of the product before a sense of value is achieved. Any experienced Excel user remembers when they first began using the program and how inefficient it seemed. Once the ability to move around in the program is gained, the utility of using a spreadsheet is apparent. The same is true of Mathcad.

One possible method of reinforcing Mathcad use beyond the elementary course is to provide a sample booklet that shows how the program can be used in a variety of applications. By preparing a booklet showing a solution for a relatively easy sample problem from each course the instructor can demonstrate the versatility of the program. By using these problems in the instruction of various courses within the curriculum and requiring certain homework assignments to be submitted in Mathcad format, instructors within a department can reinforce the utility of the program and gradually aide in the development of basic Mathcad skills.

Assembling the booklet with faculty input is essential to ensure the problems shown are indicative of those that will be learned in each course. In addition, the booklet provides each instructor an easy opportunity to integrate Mathcad into their class. A consistent departmental approach using this method will give each student several opportunities to use the program each semester. After only a few semesters the utility of the program should be evident to the student.

\section{Implementation}

The initial phase of implementation involves developing a list of all the required courses within the department. This course list is used to develop both the organizational structure of the booklet and to identify which instructors would be best suited to provide input for their respective course material. The goal of the booklet is to have relatively easy examples that provide a means of gradually exposing students to more and more of the features within the software. By organizing the booklet in the order of the courses taken, students can gain a sense of "walking" through the material as they progress through their academic career.

Since most curricula contain approximately forty courses, it is advisable to keep each course example to one page. This should allow the developer to include two small examples or one large example for each course. The examples problems should be taken from early in the course to allow the student the opportunity to expand his usage within the term and gain more from his experience using the program.

The problems shown in the booklet should be based upon actual concepts with which the instructor intends the student to be proficient so that the utility of the program is emphasized.

"Proceedings of the 2005 American Society for Engineering Education Annual Conference \& Exposition Copyright (C) 2005, American Society for Engineering Education” 
Ideally the instructor will encourage the use of the program for homework assignments at points throughout the course to bolster the idea that the faculty recognizes the benefit of the technology. While electronic homework submittals inherently open the door to integrity issues and plagiarism, the benefit of using the technology far outweighs the potential for abuse. Indeed, if professionals within industry and academia truly believe in the need for proficiency in the technological tools used in the practice of engineering, then the need for incorporating these tools into the classroom is inevitable. One way to mitigate the impact of potential integrity issues is to weight assignments using Mathcad slightly less than other handwritten assignments.

A secondary benefit of developing this tool is that the electronic file can be distributed to the faculty. This prepared material gives faculty who are unfamiliar with the program an opportunity to easily integrate the technology into the classroom. The preparation of examples and becoming familiar with the program within a given course is simplified by having organized, course specific examples that were developed with the instructor's input. The process used to develop the booklet should allow the examples within the booklet to feed directly into the course content.

\section{Assessment}

The second phase of the program involves developing a feedback mechanism to evaluate the utility of the booklet, provide a means of assessing and improving the content, provide a means of updating content to adapt to curriculum changes and give students a voice in the development of the material. Since the author is in the initial phase of development for this material, the assessment phase is beyond the scope of this paper. The author hopes to implement this product early next term to coincide with the first year of the institution's next ABET evaluation cycle. An assessment tool, such as a survey, will either be included in the booklet itself or distributed on a yearly basis to civil engineering technology students to evaluate how the material is being used and whether it is perceived as beneficial to the student.

\section{Conclusion}

With the many software packages in the marketplace today, choosing software to use in class and ensuring the student can utilize the software chosen both during college and afterwards can be a difficult task. Mathcad provides a general template for an engineer to perform a wide variety of design tasks. The format of the program lends itself to civil engineering based its ability to perform design work with the same application that serves as a report for review. By eliminating the report generation phase of the process, engineers can quickly go from design to submittal and increase profitability. Development of standardized, reviewable documents can mitigate risk. Both of these qualities have appeal for the new civil engineer.

A comprehensive, organized approach encompassing many courses can present Mathcad as a useful tool for their future careers. In addition, consistent exposure to the program supports the material presented in elementary courses and reassures the student that the earlier material did indeed have value.

"Proceedings of the 2005 American Society for Engineering Education Annual Conference \& Exposition Copyright (C) 2005, American Society for Engineering Education” 


\section{Biography}

BRIAN L. HOUSTON is an Assistant Professor of Civil Engineering Technology at the University of Pittsburgh at Johnstown and Managing Partner of Roundtable Engineering Solutions, LLC. Prior to academia, he worked as a Senior Design Engineer in the petrochemical industry and is licensed in several states. He received a B.A. from Northwestern University in 1986, and a B.S./M.S. in Civil Engineering from Oklahoma State University in $1997 / 99$. 